\title{
Predicting alcohol use with a recoding-free variant of the Implicit association test
}

Citation for published version (APA):

Houben, K. M. P. I., Rothermund, K., \& Wiers, R. W. H. J. (2009). Predicting alcohol use with a recodingfree variant of the Implicit association test. Addictive Behaviors, 34, 487-489.

https://doi.org/10.1016/j.addbeh.2008.12.012

Document status and date:

Published: 01/01/2009

DOI:

10.1016/j.addbeh.2008.12.012

Document Version:

Publisher's PDF, also known as Version of record

Document license:

Taverne

Please check the document version of this publication:

- A submitted manuscript is the version of the article upon submission and before peer-review. There can be important differences between the submitted version and the official published version of record.

People interested in the research are advised to contact the author for the final version of the publication, or visit the DOI to the publisher's website.

- The final author version and the galley proof are versions of the publication after peer review.

- The final published version features the final layout of the paper including the volume, issue and page numbers.

Link to publication

\footnotetext{
General rights rights.

- You may freely distribute the URL identifying the publication in the public portal. please follow below link for the End User Agreement:

www.umlib.nl/taverne-license

Take down policy

If you believe that this document breaches copyright please contact us at:

repository@maastrichtuniversity.nl

providing details and we will investigate your claim.
}

Copyright and moral rights for the publications made accessible in the public portal are retained by the authors and/or other copyright owners and it is a condition of accessing publications that users recognise and abide by the legal requirements associated with these

- Users may download and print one copy of any publication from the public portal for the purpose of private study or research.

- You may not further distribute the material or use it for any profit-making activity or commercial gain

If the publication is distributed under the terms of Article $25 \mathrm{fa}$ of the Dutch Copyright Act, indicated by the "Taverne" license above, 


\title{
Predicting alcohol use with a recoding-free variant of the Implicit Association Test
}

\author{
Katrijn Houben $^{\mathrm{a}, *}$, Klaus Rothermund ${ }^{\mathrm{b}}$, Reinout W. Wiers ${ }^{\mathrm{c}}$ \\ a Clinical Psychological Science, Maastricht University, PO BOX 616, 6200 MD Maastricht, The Netherlands \\ b Friedrich-Schiller-University Jena, Germany \\ c University of Amsterdam, The Netherlands
}

\section{A R T I C L E I N F O}

\section{Keywords:}

Alcohol

Implicit cognition

Implicit Association Test

IAT-RF

Recoding

\begin{abstract}
A B S T R A C T
Recently, a modified version of the Implicit Association Test (IAT), the IAT-RF (IAT-Recoding Free) was developed which prevents recoding processes by switching response assignments randomly between trials rather than between blocks. In this study, the IAT-RF was used to measure and examine the predictive validity of recoding-free implicit alcohol associations with positive arousal. Findings with the IAT-RF demonstrated that alcohol was overall more strongly associated with negative sedation than with positive arousal. However, more importantly, the size of this compatibility effect was positively correlated with alcohol use indicating that stronger implicit alcohol associations with positive arousal are related to increased drinking. Further, implicit alcohol associations with positive arousal measured with the IAT-RF also predicted unique variance in alcohol use above the variance explained by explicit measures. Hence, the present findings suggest that implicit associations with positive arousal may play an important role in drinking behavior, and demonstrate the validity of the IAT-RF as a measure of implicit alcohol associations. (C) 2009 Elsevier Ltd. All rights reserved.
\end{abstract}

\section{Introduction}

Dual-process models stress that addictive behaviors, such as alcohol abuse, are steered by both controlled and automatic or implicit cognitive processes (e.g., Wiers et al., 2007). This understanding of addictive behaviors in terms of two semi-independent cognitive processes has stimulated the use of indirect measures of implicit alcohol-related cognitions, such as the Implicit Association Test (IAT; Greenwald, McGhee, \& Schwartz, 1998). Studies using the IAT demonstrated implicit alcohol associations with negative affect that are negatively related to drinking (e.g., De Houwer, Crombez, Koster, \& De Beul, 2004; Houben \& Wiers, 2006, 2007; Wiers, van Woerden, Smulders, \& de Jong, 2002), and implicit alcohol associations with arousal that predict increased drinking (e.g., Wiers et al., 2002).

However, compatibility effects in the IAT are not necessarily based on implicit memory associations but can also be influenced by recoding processes that obscure the interpretation of IAT effects (Rothermund, Wentura, \& De Houwer, 2005). Recoding means that there exists a feature (e.g., salience or familiarity) that allows a simple mapping of one target and one attribute category onto one response (e.g., because exemplars of both categories are familiar) and of the other target and attribute category to the other response (e.g., because exemplars of these categories are unfamiliar). Target and/or attribute stimuli can thus be categorized on the basis of other features than the "nominal definitions" of the categories. Although Houben and Wiers

\footnotetext{
* Corresponding author. Clinical Psychological Science, Maastricht University, PO Box 616, 6200 MD Maastricht, The Netherlands.

E-mail address: K.Houben@psychology.unimaas.nl (K. Houben).
}

(2006) demonstrated that recoding in terms of salience cannot fully account for all of the effect variance in an alcohol-IAT, these findings do not exclude the possibility that salience as well as other types of recoding might affect alcohol-IATs.

To overcome this problem, Rothermund, Teige-Mocigemba, Gast, and Wentura (2009) introduced the IAT-RF (Recoding-Free IAT), which eliminates recoding by switching response assignments of categories randomly between trials within a single block, rather than between blocks as in the standard IAT. Hence, the IAT-RF could be a valuable alternative to the standard IAT for studying alcohol-related implicit processes. Here, we examined whether compatibility effects in the IAT-RF predict unique variance in drinking behavior above explicit cognitions. Further, unlike previous studies where implicit alcohol associations with positive affect and arousal were assessed using separate IATs (e.g. Wiers et al., 2002), implicit alcohol associations with positive arousal were measured in a single IAT-RF. Wiers et al. (2002) demonstrated that a composite of implicit arousal associations and implicit affective associations predict unique variance in alcohol use, suggesting that implicit alcohol associations with positive arousal are important predictors of drinking. By eliminating confounding due to recoding, this study provides a pure test of the predictive validity of implicit alcohol associations with positive arousal.

\section{Methods}

Participants were 52 male heavy drinkers (Mean age $=21.79$ years, $\mathrm{SD}=4.00$; alcohol use: $M=28.58$ servings of $10 \mathrm{~g} /$ week, $\mathrm{SD}=10.98$, assessed with the timeline follow-back method (TLFB; Sobell \& Sobell, 1990); alcohol problems: $M=14.06, S D=3.72$, on the Alcohol Use 
Disorder Identification Test (AUDIT; Saunders, Aasland, Babor, De la Fuente, \& Grant, 1993), and $M=.78, \mathrm{SD}=.35$, on the Rutgers Alcohol Problem Index (RAPI; White \& Labouvie, 1989)). The IAT-RF consisted of three blocks. In the first block (20 trials), participants practiced the classification of attribute stimuli into a positive arousal and a negative sedation category (see Appendix). The response assignment of the attribute categories was counterbalanced. In the second block (20 trials), participants practiced the classification of target stimuli into alcohol and soft drinks (see Appendix). During this block, the response assignment of the target categories switched randomly between trials with the restriction that each target was presented once in each response assignment. In the third block (160 trials), participants had to classify both target and attribute stimuli with switching response assignments for the target categories. Response assignments switched randomly between trials with the restriction that half of the trials were presented in one response assignment (e.g., positive arousal+ alcohol vs. soft drinks + negative sedation) and the other half of the trials in the other response assignment (positive arousal + soft drinks vs. alcohol+negative sedation). Stimuli were presented randomly in the middle of the computer screen. Category labels were presented on the left and right of the presented stimulus in accordance with the response assignment, $1500 \mathrm{~ms}$ before the upcoming stimulus. The intertrial interval was 250 ms. Explicit Alcohol-Related Expectancies were assessed with an expectancy questionnaire. Participants indicated on a $100 \mathrm{~mm}$ Visual Analogue Scale (VAS) how much they agreed $(0=$ disagree, $100=$ agree $)$ with the statement "After drinking alcohol, I feel ...", which was completed with the same words used in the IAT-RF, including the labels. Explicit Attitudes toward Alcohol were measured with 2 semantic differentials: Participants indicated on a $100 \mathrm{~mm}$ VAS how much they considered drinking alcohol to be unpleasant-pleasant, and boring-fun (higher values on the scales indicate more positive attitudes). Participants first received the IAT-RF and then the questionnaires.

\section{Results}

Response latencies in the IAT-RF were log-transformed and aggregated separately for trials with compatible (alcohol+positive arousal vs. soft drinks + negative sedation) and incompatible (alcohol + negative sedation vs. soft drinks + positive arousal) response assignments. The compatibility effect was calculated as the difference between these two means so that higher scores indicate faster performance during the compatible combination than during the incompatible combination. This effect was significant, $t(52)=-2.25$, $p=.029$, indicating faster performance during the alcohol-negative sedation combination $(M=932 \mathrm{~ms}, \mathrm{SD}=261)$ than during the alcoholpositive arousal combination $(M=945 \mathrm{~ms}$; $S D=255)$. Further, mean scores were calculated for negative expectancies $(M=23.71, \mathrm{SD}=9.92)$, positive expectancies $(M=69.22, \mathrm{SD}=10.28)$, and attitudes $(M=76.81$, $\mathrm{SD}=9.63$ ). Explicit expectancies and attitudes were not significantly correlated with IAT-RF effects (Table 1).

Next, alcohol use was estimated from the TLFB and alcohol-related problems were estimated as the mean of the $z$-transformed RAPI and

Table 1

Correlations of compatibility effects in the IAT-RF, explicit alcohol-related expectancies and attitudes, and self-reported alcohol use and alcohol-related problems

\begin{tabular}{|c|c|c|c|c|c|c|}
\hline & \multirow[t]{2}{*}{ IAT-RF } & \multicolumn{2}{|c|}{ Expectancies } & \multirow[t]{2}{*}{ Attitude } & \multicolumn{2}{|c|}{ Alcohol } \\
\hline & & Positive & Negative & & Use & Problems \\
\hline IAT-RF & - & & & & & \\
\hline Positive expectancies & .15 & - & & & & \\
\hline Negative expectancies & .07 & $-.49 * *$ & - & & & \\
\hline Attitudes & $.24^{\#}$ & $.40^{* *}$ & $-.25^{\#}$ & - & & \\
\hline Alcohol use & $.35^{*}$ & .22 & -.21 & $.33^{*}$ & - & \\
\hline Alcohol problems & $.24^{\#}$ & -.05 & $.35^{*}$ & .15 & $.41^{* *}$ & - \\
\hline
\end{tabular}

Note. ${ }^{* *}=p<0.01$ (2-tailed), ${ }^{*}=p<0.05$ ( 2 -tailed), ${ }^{*}=p<0.10$ ( 2 -tailed).
Table 2

Summary of hierarchical regression analyses for the prediction of self-reported alcoho use and alcohol-related problems by explicit attitudes and IAT-RF compatibility effects ${ }^{\mathrm{a}}$

\begin{tabular}{|c|c|c|c|c|c|c|c|}
\hline Step & Variable & $B$ & SE $B$ & $\beta$ & $\operatorname{SE} \beta$ & $t$ & $P$ \\
\hline \multicolumn{8}{|c|}{ Alcohol use } \\
\hline 1 & Attitude & .35 & .14 & .33 & .13 & 2.43 & .019 \\
\hline \multirow[t]{2}{*}{2} & Attitude & .27 & .14 & .26 & .13 & 1.92 & .061 \\
\hline & IAT-RF & 47.69 & 22.10 & .29 & .13 & 2.16 & .035 \\
\hline \multicolumn{8}{|c|}{ Alcohol problems } \\
\hline 1 & Negative expectancies & .03 & .01 & .35 & .13 & 2.66 & .010 \\
\hline \multirow[t]{2}{*}{2} & Negative expectancies & .03 & .01 & .34 & .13 & 2.59 & .013 \\
\hline & IAT-RF & 3.12 & 1.84 & .22 & .13 & 1.69 & .097 \\
\hline
\end{tabular}

Note. Alcohol use: $F(1,50)=5.92, p=.019, R^{2}=.11$, for step $1 ; F_{\text {change }}(1,49)=4.68, p=.035$, $R_{\text {change }}^{2}=.08$, for step 2. Final model: $R^{2}=.18, R_{\text {adjusted }}^{2} .15, F(2,49)=5.52, p=.007$ Alcohol-related problems: $F(1,50)=7.08, p=.010, R^{2}=.12$, for step $1 ; F_{\text {change }}(1,49)=$ $2.89, p=.097, R_{\text {change }}^{2}=.05$, for step 2 . Final model: $R^{2}=.17, R_{\text {adjusted }}^{2}=.14, F(2,49)=5.10$, $p=.010$.

a IAT-RF compatibility effects were scored so that positive values indicate faster responses if alcohol and positive arousal (and soft drinks and negative sedation) were assigned the same response; higher values on the attitude measure indicate more positive attitudes toward drinking alcohol.

AUDIT scores. IAT-RF effects were significantly correlated with alcohol use (Table 1), indicating that stronger implicit alcohol associations with positive arousal are related to higher levels of alcohol use. The incremental validity of the IAT-RF was tested in a hierarchical regression analysis predicting alcohol use. Explicit attitudes, entered in step 1 , significantly predicted alcohol use, and compatibility effects in the IAT-RF, entered in step 2, significantly predicted alcohol use above explicit attitudes (Table 2). Similarly, we examined the incremental validity of the IAT-RF for the prediction of alcohol-related problems. Negative expectancies, entered in step 1, significantly predicted alcohol-related problems, and IAT-RF compatibility effects predicted alcohol-related problems at borderline significance above negative expectancies in step 2 (Table 2 ).

\section{Discussion}

The present findings attest to the usefulness of the IAT-RF for studying implicit associations underlying alcohol use. First, we found stronger implicit alcohol associations with negative sedation than with positive arousal, when recoding influences were prevented. This result is consistent with previous studies demonstrating stronger implicit alcohol associations with negative affect than with positive affect (e.g., De Houwer et al., 2004; Houben \& Wiers, 2006, 2007; Wiers et al., 2002). However, compatibility effects in previous studies were notably larger than the compatibility effect in this study. Possibly, the combination of affect with arousal resulted in smaller compatibility effects in this study, since previous studies have demonstrated both implicit alcohol associations with negative affect and with arousal (e.g., De Houwer et al., 2004; Wiers et al., 2002). In addition, we used the IAT-RF that eliminates recoding processes, which may also have reduced compatibility effects compared to previous studies that used the standard IAT. In line with this reasoning, smaller and reversed compatibility effects indicating more positive implicit attitudes towards alcohol have been found with indirect measures that are relatively uninfluenced by recoding, such as the Extrinsic Affective Simon Task (EAST; De Houwer, 2003; e.g., de Jong, Wiers, van de Braak, \& Huijding, 2007).

Second, the IAT-RF predicted unique variance in alcohol use above the variance explained by explicit cognitions. Specifically, stronger implicit alcohol associations with positive arousal (or weaker implicit alcohol associations with negative sedation), predict increased levels of drinking. These findings are consistent with previous research using standard IATs demonstrating that stronger implicit alcohol associations with positive affect and with arousal predict increased alcohol consumption above the variance in drinking behavior explained by 
explicit cognitions (e.g., Wiers et al., 2002). Moreover, implicit alcohol associations were also largely unrelated to explicit alcohol-related cognitions. Hence, the present findings suggest that drinking behavior is influenced by two semi-independent cognitive processes that predict unique variance in alcohol use.

\section{Acknowledgments}

Katrijn Houben, Department of Clinical Psychological Science, Maastricht University, The Netherlands; Klaus Rothermund, Department of Psychology, Friedrich-Schiller-University Jena, Germany. Reinout W. Wiers, Department of Psychology, University of Amsterdam. This research was funded by "VIDI" grant 452.02.005 from the Dutch National Science Foundation (N.W.O.). Correspondence concerning this article should be addressed to Katrijn Houben, Clinical Psychological Science; Maastricht University; PO BOX 616; 6200 MD Maastricht, The Netherlands. E-mail: K.Houben@psychology.unimaas.nl.

\section{Appendix A}

\section{Target stimuli}

Alcohol: beer, wine, whisky, drink, vodka.

Soft drinks: Fanta, Coke, Sprite, sinas (lemonade), ice-tea.

Stimuli of the (Dutch) alcohol and soft drinks categories were matched on familiarity $(M=5.07, \mathrm{SD}=1.23$, and $M=4.81, \mathrm{SD}=1.43$, respectively; $1=$ completely unfamiliar, $7=$ very familiar), valence $(M=4.49, \mathrm{SD}=.83$, and $M=4.53, \mathrm{SD}=.83$, respectively; $1=$ extremely negative, $7=$ extremely positive), arousal $(M=4.37, \mathrm{SD}=.87$, and $M=4.62, \mathrm{SD}=1.00$, respectively; 1 = extremely passive, 7 = extremely active), and number of syllables.

\section{Attribute stimuli}

Active: cheerful, energetic, lively, excited, chatty.

Miserable: cheerless, horrible, nauseous, unhappy, listless.

Stimuli of the (Dutch) positive arousal ('active') category and the negative sedation ('miserable') category, respectively, scored high $(M=6.15, \mathrm{SD}=.55)$ and low in affective value $(M=1.52, \mathrm{SD}=.50)$, and respectively, also scored high $(M=6.26, \mathrm{SD}=.46)$ and low $(M=1.88$, $\mathrm{SD}=.52$ ) on arousal. Stimuli of the two attribute categories were matched on familiarity $(M=5.77, \mathrm{SD}=.79$, and $M=3.69, \mathrm{SD}=1.62$, respectively) and number of syllables.

\section{References}

De Houwer, J. (2003). The Extrinsic Affective Simon Task. Experimental Psychology, 50, 77-85.

De Houwer, J., Crombez, G., Koster, E. H. W., \& De Beul, N. (2004). Implicit alcoholrelated cognitions in a clinical sample of heavy drinkers. Journal of Behavior Therapy and Experimental Psychiatry, 35, 275-286.

de Jong, P. J., Wiers, R. W., van de Braak, M., \& Huijding, J. (2007). Using the Extrinsic Affective Simon Test as a measure of implicit attitudes toward alcohol: Relationship with drinking behavior and alcohol problems. Addictive Behaviors, 32, 881-887.

Greenwald, A. G., McGhee, D. E., \& Schwartz, J. L. K. (1998). Measuring individual differences in implicit cognition: The Implicit Association Test. Journal of Personality and Social Psychology, 74, 1464-1480.

Houben, K., \& Wiers, R. W. (2006). A test of the salience asymmetry interpretation of the Alcohol-IAT. Experimental Psychology, 53, 292-300.

Houben, K., \& Wiers, R. W. (2007). Personalizing the alcohol-IAT with individualized stimuli: Relationship with drinking behavior and drinking-related problems. Addictive Behaviors, 32, 2852-2864.

Rothermund, K., Teige-Mocigemba, S., Gast, A., \& Wentura, D. (2009). Eliminating the influence of recoding in the Implicit Association Test: The Recoding-Free Implicit Association Test (IAT-RF). Quarterly Journal of Experimental Psychology, 62, 84-98.

Rothermund, K. Wentura, D. \& De Houwer, J. (2005). Validity of the salience asymmetry account of the IAT: Reply to Greenwald, Nosek, Banaji, and Klauer (2005). Journal of Experimental Psychology: General, 134, 426-430.

Saunders, J. B., Aasland, O. G., Babor, T. F., De la Fuente, J. R., \& Grant, M. (1993). Development of the Alcohol use Disorders Identification Test (AUDIT): WHO collaborative project on early detection of persons with harmful alcohol consumption. Addiction, 88, 791-804.

Sobell, L. C., \& Sobell, M. B. (1990). Self-report issues in alcohol abuse: State of the art and future directions. Behavioral Assessment, 12, 77-90.

White, H. R., \& Labouvie, E. W. (1989). Towards the assessment of adolescent problem drinking. Journal of Studies on Alcohol, 50, 30-37.

Wiers, R. W., Bartholow, B. D., van den Wildenberg, E., Thush, C., Engels, R. C. M. E., Sher, K. J., et al. (2007). Automatic and controlled processes and the development of addictive behaviors in adolescents: A review and a model. Pharmacology, Biochemistry and Behavior, 86, 263-283.

Wiers, R. W., van Woerden, N., Smulders, F. T. Y., \& de Jong, P. J. (2002). Implicit and explicit alcohol-related cognitions in heavy and light drinkers. Journal of Abnormal Psychology, 111, 648-658. 